\title{
EXTRAÇÃO POR PRENSAGEM E POR SOLVENTE DE ÓLEO PROVENIENTE DA BORRA DE CAFÉ PARA PRODUÇÃO DE BIODÍESEL E FUTURO ESTUDO DA GLICERINA GERADA
}

\author{
D. R. LEMBRANCE${ }^{1}$, Y. S. P. PESSANHA², W. M. POUBEL ${ }^{1}$ \\ ${ }^{1}$ Universidade Federal do Espírito Santo, Departamento de Engenharia Rural \\ ${ }^{2}$ Universidade Federal do Rio de Janeiro, Escola de Química \\ E-mail para contato: wmpoubel@gmail.com
}

\begin{abstract}
RESUMO - O pó residual do preparo do café, na maioria das vezes, é descartado de forma indevida. Estudos mostram que da borra de café pode-se retirar óleo, que ao ser misturado com álcool, na presença de um catalisador, pode ser usada para obtenção do biodiesel e de glicerina. Utilizando dispositivos de extração; prensa hidráulica e suporte para prensagem e extração de material (matriz de extração), foram realizados experimentos para a obtenção do óleo, sendo possível notar que com o aumento da pressão aplicada sobre a amostra pode-se obter o produto desejado, no entanto, foi obtido em proporções indesejavelmente baixas, com rendimento insatisfatório de aproximadamente $0,015 \%$. Este trabalho segue como base para estudos de extração por solvente orgânico, para obtenção dos produtos finais em quantidades expressivas, sendo fundamental para um maior entendimento sobre suas características, assim como um novo estudo para uma nova destinação para a glicerina.
\end{abstract}

\section{INTRODUÇÃO}

Muitas pesquisas são apresentadas todos os anos, no meio acadêmico, referentes à reutilização de rejeitos das mais diversas origens e que a cada ano são continuamente destinados a mananciais, rios e oceanos. De acordo com a Organização Internacional do Café - OIC, em relatório de mensal referente ao mês de janeiro, o Brasil teve uma produção, em 201409 , de aproximadamente 36,3 milhões de sacas do grão o que totaliza aproximadamente 2,18 milhões de toneladas. Com isso tem-se uma quantidade imensa do pó de café residual da produção da bebida que é extremamente conhecida em todo o mundo e que a cada dia ganha mais e mais adeptos.

Em todos os setores da indústria mundial a preocupação com a reutilização de rejeitos para a geração de economia é grandemente discutida. De acordo com a Confederação Nacional da Indústria (CNI), em publicação no Encontro da Indústria para a Sustentabilidade do ano de 2012, a combinação do uso sustentável de matéria prima e energia é uma realidade possível e relevante à todos os setores industriais, assim, todo o esforço e estudo que venha a facilitar tal realidade é bem vindo e de grande importância para a humanidade. 
A demanda de energia vem crescendo a cada ano em todo o mundo, e com o crescimento populacional, a tendência é que aumente ainda mais. Segundo o Relatório Mundial das Nações Unidas sobre o Desenvolvimento de Recursos Hídricos (WWDR4), se nenhuma atitude sustentável for tomada em larga escala, até o ano de 2035 serão necessários um aumento de $50 \%$ na produção de energia para suprir a demanda mundial.

A reutilização da borra do café para obtenção de energia vem a ser justificada, a princípio, pela alta quantidade deste rejeito, que, por exemplo, vem sendo jogado no meio ambiente indiscriminadamente, e o que corrobora a importância da reutilização da borra de café é a importância da obtenção de novas fontes de energia para o setor industrial brasileiro e mundial. Para maior estudo de tal alternativa, este projeto objetiva-se no entendimento de todo o processo de extração do óleo, produção do biodiesel, análise e estudos de novos projetos para a correta destinação do subproduto glicerina, obtida pela produção do combustível em questão.

Segundo Almeida e Spagarino (2012), biodiesel é um combustível alternativo, gerado a partir a reação, denominada transesterificação, de gorduras animais e ou óleos vegetais na presença de um catalizador, geralmente alcalino, com algum álcool. Os produtos da transesterificação são ésteres de alquila ou ésteres metílicos (quando o se tem o metanol como álcool), e o glicerol mais conhecido como glicerina.

\section{MATERIAIS E METODOLOGIA}

Os experimentos foram realizados no Laboratório 2 de Engenharia Química, LEQ 2 da Universidade Federal do Espírito Santo - Campus Alegre. Vale ressaltar que todas as tentativas e extrações foram realizadas durante o mês de dezembro.

As temperaturas que foram observadas durante as atividades variaram dos 22 aos $26^{\circ} \mathrm{C}$ e devido a localização geográfica da cidade de alegre, que se encontra a uma altitude de $238 \mathrm{~m}$, pode ser medido em um barômetro de Torricelli uma pressão atmosférica de $745 \mathrm{mmHg}$ ou aproximadamente $0,98 \mathrm{~atm}$.

A Figura 1 apresenta de forma sucinta todo o procedimento para a realização e andamento do projeto: 
Figura 1 - Esquema resumido das etapas do projeto.

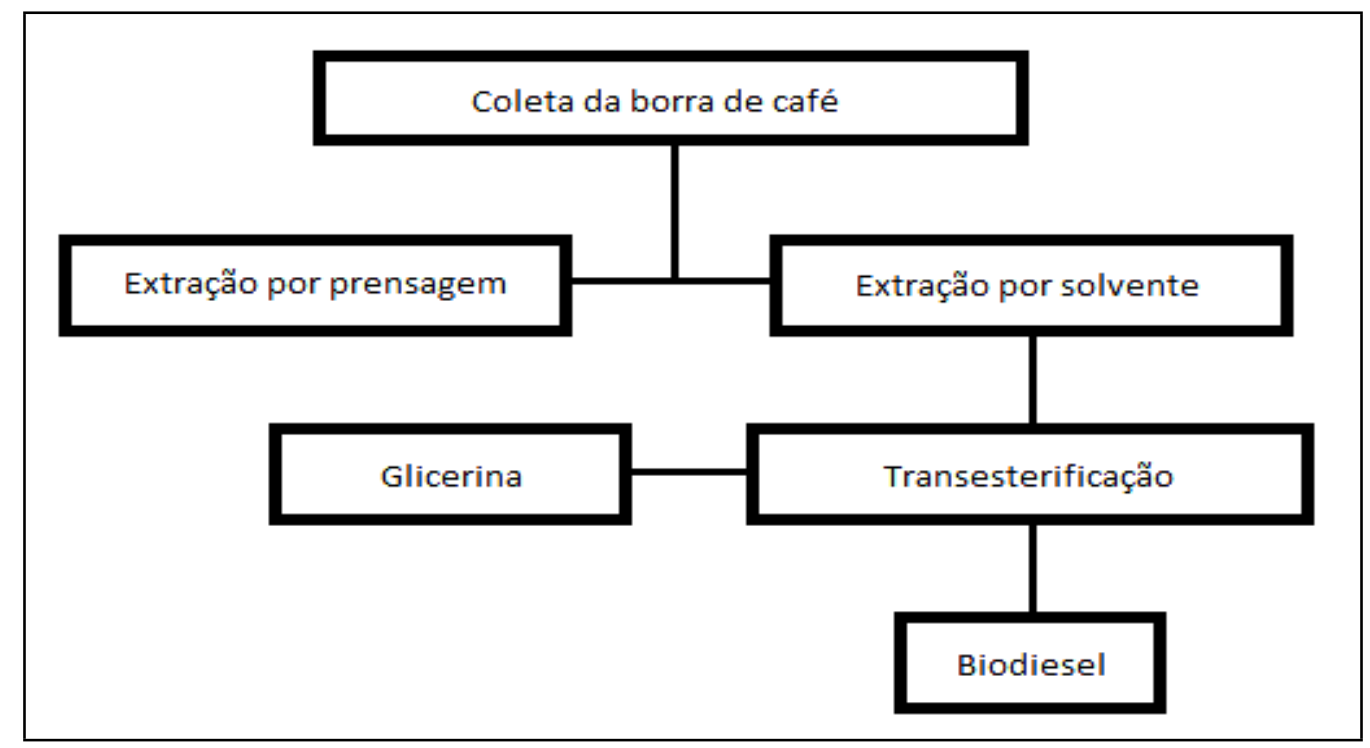

A coleta da borra do café foi realizada com ajuda de colaboradores que estocavam a borra logo após a etapa de extração para fazer a bebida do café. Foram distribuídos, previamente, recipientes abertos para a locação de tal rejeito e assim que estivesse seco, ao ar livre, o material era recolhido pelos realizadores do estudo.

Todo material foi devidamente secado em e estufa por cerca de 1 hora em temperatura de $70^{\circ} \mathrm{C}$ e consequentemente guardados em sacos de coleta e pesados utilizando-se de uma balança de precisão com capacidade de $3000 \mathrm{~g}$.

$\mathrm{Na}$ primeira etapa do trabalho realizado, foi feita a tentativa da extração do óleo proveniente da borra de café pelo método de extração por prensagem, com uso de uma prensa hidráulica com capacidade de 15 toneladas. Para tal, foi utilizada uma matriz de extração cilíndrica com uma área de seção transversal interna de aproximadamente $0,045 \mathrm{~m}^{2}$.

A Figura 2 apresenta o desenho técnico da matriz de extração, feito no primeiro diedro, sendo apresentadas em duas vistas, uma vista superior e uma vista inferior, tendo suas dimensões em milímetros: 
Figura 2 - Desenho técnico do modelo da matriz de extração utilizada.
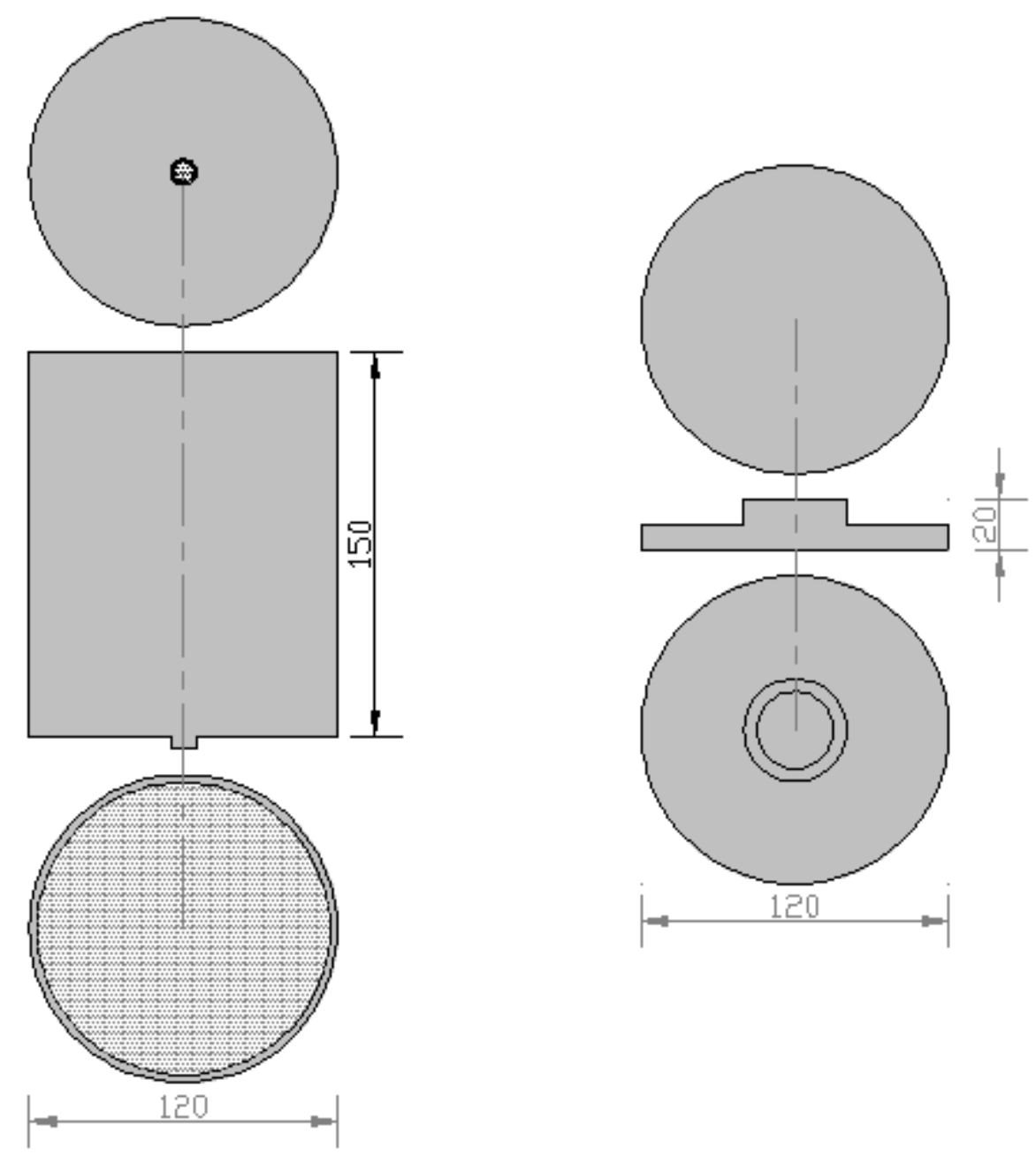

Em uma segunda etapa de extração foi utilizada uma matriz de extração cilíndrica do mesmo modelo que a matriz da primeira extração, porém com uma área de seção transversal interna de aproximadamente $0,00125 \mathrm{~m}^{2}$.

Tais matrizes são compostas por seus respectivos corpos cilíndricos, suas tampas apresentam um engate para a prensa hidráulica, além de uma estrutura interna vazada constituída em material polimérico que recebe o pó para compactação, a prensa possui ainda um furo na parte inferior do corpo cilíndrico para saída do óleo. Com exceção da parte interna produzida em material polimérico, todo o restante da estrutura é feita em aço.

Para a terceira extração está programado o uso de um extrator do tipo Soxhlet, adaptado a uma manta de aquecimento, tendo como solvente hexano ou éter de petróleo, e também uma extração com agitação e aquecimento em béquer, tendo como solvente etanol ou hexano. $\mathrm{O}$ esquema do extrator Soxhlet com manta de aquecimento pode ser observado na Figura 3 de acordo com Nielsen (2003). 
Figura 3 - Extrator do tipo Soxhlet com manta de aquecimento.

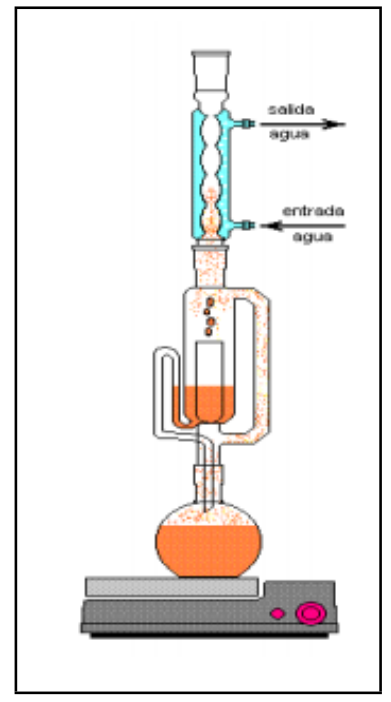

\section{RESULTADOS E DISCUSSÃO}

A primeira etapa teste de extração, realizada com uso de um prensa hidráulica e de uma matriz de extração com área de seção transversal de $0,045 \mathrm{~m}^{2}$, o que implica que a área de contato com os $350 \mathrm{~g}$ de borra de café, corresponde a esta mesma medida, teve uma carga aplicada de 10 toneladas por cerca de 15 minutos, o que nos dá uma pressão de aproximadamente $2178 \mathrm{MPa}$, sendo admitida a aceleração da gravidade como 9,80 m/s .

Tal extração se mostrou ineficaz, tendo como resultado apenas resquícios mínimos do óleo, tanto que não foi possível sua quantificação com uso da balança de precisão. Segundo Ravindranath (1972), que conseguiu um aproveitamento em massa entre 8 e 17\% do óleo por extração com solvente, os grãos da borra de café não apresentam quantidades significativamente altas, que possam ser facilmente retiradas por prensagem, o que justifica o baixíssimo teor conseguido com este primeiro ensaio.

A fim de aumentar a quantidade de óleo extraído da borra, uma segunda tentativa com uso da prensa hidráulica foi feita, sendo agora utilizada a matriz de extração com área de contato com o pó de $0,00125 \mathrm{~m}^{2}$ aproximadamente.

Foram utilizados 60 gramas da borra de café, sendo aplicada a mesma carga utilizada na tentativa anterior e o mesmo tempo de prensagem, porém como a área de contato é menor a pressão exercida sobre a amostra foi bem maior, totalizando $78400 \mathrm{Mpa}$. Com isso pode-se extrair uma quantidade maior que a da primeira tentativa, cerca de $1 \mathrm{ml}$, o que também não se mostrou satisfatório, sendo computado um rendimento de aproximadamente $0,015 \%$, rendimento muito abaixo do já citado anteriormente (RAVINDRANATH, 1972).

Tal rendimento, inferior aos resultados já encontrados na literatura, pode ser justificado ao fato de ter sido usada uma prensa hidráulica, onde é mais indicado o uso de uma prensa contínua. 
Com base nos resultados obtidos com a prensagem, no exato momento estão sendo organizados os materiais para utilização de um extrator do tipo Soxhlet, com o uso de solventes orgânicos para a retirada do óleo da amostra.

Com base em trabalhos sobre o mesmo tema, que mostram a possibilidade da extração do óleo em questão, está sendo montado um novo grupo de pesquisa que, após a obtenção do óleo e produção do biodiesel por transesterificação, também está preparado para tratar a glicerina gerada, através de estudos associadas a catalisadores específicos, para definir um destino a este subproduto gerado em grande escala atualmente.

\section{CONCLUSÃO}

Com base nos resultados obtidos com a fase inicial deste trabalho, pode-se concluir que a extração do óleo da borra de café é possível, visto que com o método de extração, julgado mais inferior, já foi possível obter, mesmo que em quantidade insatisfatória, uma porção do mesmo. Sendo decidida a próxima etapa do trabalho através de extração por solventes orgânicos, tal projeto se mostra promissor para o estudo da produção do biodiesel, assim como um estudo de suas características, e também as da glicerina, sendo ainda proposto através deste trabalho um novo projeto para destinação da mesma.

\section{REFERÊNCIAS}

ALMEIDA, D. T. L.; SPAGARINO, G. Estudo da Viabilidade da Produção de Biodiesel a Partir de Óleo de Borra de Café Extraído com Etanol. Dissertação para obtenção do título de graduação em Engenharia Química. Escola Politécnica da Universidade Federal de São Paulo, São Paulo, 2012.

Encontro da indústria para a Sustentabilidade. Avanços da Indústria Rumo ao Desenvolvimento Sustentável, Brasília, 2012. Disponível em: http://www.fiemt.com.br/arquqivos/917_cni_parte_2_rio20_web.pdf. Acesso em 20 de janeiro de 2015.

NIELSEN, S. Food Analysis Laboratory Manual. New York: Kluwer Academic Plenum Publishers, 2003.

Organização Internacional do Café - OIC. Relatório sobre o mercado de café, janeiro de 2015.2 Disponível em: http://consorciopesquisacafe.com.br/arquivos/consorcio/publicacoes_tecnicas/Janeiro_2015.p df. Acesso em 26 de março de 2015.

RAVINDRANATH, R.; YOUSUF ALI KHAN, R.; OBY REDDY, T. THIRUMALA RAO, S.D. REDDY, B.R. Composition and Characteristics of Indian Coffee Bean, Spent Ground and Oil. Journal of the Science of Food and Agriculture, v. 23, p. 307-310, 1972.

Relatório Mundial das Nações Unidas. Desenvolvimento dos Recursos Hídricos, 2014. Disponível em: http://www.unesco.org/new/filedmin/MULTIMEDIA/FIELD/Brasilia/pdf/ WWDR4\%20Background\%20Briefing\%20Note_pt_2012.pdf. Acesso em 13 de janeiro de 2015. 